\title{
Correction: Using Participatory Design Methodologies to Co-Design and Culturally Adapt the Spanish Version of the Mental Health eClinic: Qualitative Study
}

Laura Ospina-Pinillos ${ }^{1,2}$, MD; Tracey Davenport ${ }^{1}, \mathrm{BA}$ (Hons), EMBA; Antonio Mendoza Diaz ${ }^{3}$, BPsych, PhD; Alvaro Navarro-Mancilla ${ }^{4}$, MIPH, MD; Elizabeth M Scott ${ }^{5}$, MBBS, FRANZCP; Ian B Hickie ${ }^{1}$, MD, FRANZCP

${ }^{1}$ Brain and Mind Centre, The University of Sydney, Sydney, NSW, Australia

${ }^{2}$ Department of Psychiatry and Mental Health, Pontifical Javeriana University, Bogota, Colombia

${ }^{3}$ School of Psychiatry, Department of Medicine, University of New South Wales, Sydney, NSW, Australia

${ }^{4}$ Neuropsychiatry Research Group, Autonomous University of Bucaramanga, Bucaramanga, Colombia

${ }^{5}$ School of Medicine, University of Notre Dame Australia, Sydney, NSW, Australia

Corresponding Author:

Laura Ospina-Pinillos, MD

Brain and Mind Centre

The University of Sydney

Shops 1-3, 66-70 Parramatta Road

Sydney, NSW, 2051

Australia

Phone: 610286276946

Email: laura.ospinapinillos@sydney.edu.au

\section{Related Article:}

Correction of: https://www.jmir.org/2019/8/e14127/

(J Med Internet Res 2022;24(3):e37679) doi: 10.2196/37679

In "Using Participatory Design Methodologies to Co-Design and Culturally Adapt the Spanish Version of the Mental Health eClinic: Qualitative Study" (J Med Internet Res 2019;21(8):e14127), the authors noted one error.

In the originally published article, a value appeared incorrectly in the following sentence.

A total of 7 health professionals participated in the workshops; 6 were female and their ages ranged from 22 to 24 years (median age 28 years).
This has been corrected as follows:

A total of 7 health professionals participated in the workshops; 6 were female and their ages ranged from 22 to 34 years (median age 28 years).

The correction will appear in the online version of the paper on the JMIR Publications website on March 4, 2022, together with the publication of this correction notice. Because this was made after submission to PubMed, PubMed Central, and other full-text repositories, the corrected article has also been resubmitted to those repositories.

\footnotetext{
This is a non-peer-reviewed article. Submitted 02.03.22; accepted 02.03.22; published 03.03.22.

Please cite as:

Ospina-Pinillos L, Davenport T, Mendoza Diaz A, Navarro-Mancilla A, Scott EM, Hickie IB

Correction: Using Participatory Design Methodologies to Co-Design and Culturally Adapt the Spanish Version of the Mental Health eClinic: Qualitative Study

J Med Internet Res 2022;24(3):e37679

URL: https://www.jmir.org/2022/3/e37679

doi: $\underline{10.2196 / 37679}$

PMID:
} 
article distributed under the terms of the Creative Commons Attribution License (https://creativecommons.org/licenses/by/4.0/), which permits unrestricted use, distribution, and reproduction in any medium, provided the original work, first published in the Journal of Medical Internet Research, is properly cited. The complete bibliographic information, a link to the original publication on https://www.jmir.org/, as well as this copyright and license information must be included. 